\title{
Regulatory effect of rat bone marrow mesenchymal stem cells on Treg/Th17 immune balance in vitro
}

\author{
KAI WANG ${ }^{1-3^{*}}$, YAN-JUN SHI ${ }^{4 *}$, ZHUO-LUN SONG ${ }^{1-3}$, BIN WU $^{1-3}$, CHUN-LEI ZHOU ${ }^{5}$, WEI LIU ${ }^{6}$ and WEI GAO ${ }^{1-3}$ \\ ${ }^{1}$ Department of Transplant Surgery, Tianjin First Central Hospital; \\ ${ }^{2}$ Key Laboratory of Organ Transplantation of Tianjin; ${ }^{3}$ Tianjin Clinical Research Center for Organ Transplantation, \\ Tianjin 300192, P.R. China; ${ }^{4}$ Hillman Center for Pediatric Transplantation, Department of Transplant Surgery, \\ Children's Hospital of Pittsburgh of UPMC, Pittsburgh, PA 15224, USA; ${ }^{5}$ Clinical Laboratory, \\ ${ }^{6}$ Blood Transfusion Department, Tianjin First Central Hospital, Tianjin 300192, P.R. China
}

Received June 28, 2019; Accepted February 20, 2020

DOI: $10.3892 / \mathrm{mmr} .2020 .11019$

\begin{abstract}
Bone marrow mesenchymal stem cells (BM-MSCs) regulate the balance between regulatory $\mathrm{T}$ cells (Tregs) and T helper 17 (Th17) cells. However, the role of different factors on BM-MSCs-mediated regulation of the Treg/Th17 balance is unknown. BM-MSCs and $\mathrm{CD}^{+}{ }^{+} \mathrm{T}$ lymphocytes were co-cultured with various treatments. The ratio of Treg/Th17 cells was calculated and the expression of different cytokines was measured. BM-MSCs were found to have a proliferative effect on Th17 cells at a basal concentration and at a 2-fold increase in the number of BM-MSCs. However, when the number of BM-MSCs used was increased 4-fold, they had an inhibitory effect on the Th17 cells. The effect of BM-MSCs on Tregs was inhibited by the addition of tacrolimus but not rapamycin. The effect of BM-MSCs on Th17 cells was inhibited by rapamycin. Additionally, the effect of BM-MSCs on Tregs were inhibited by the addition of a transforming growth factor- $\beta$ (TGF- $\beta$ ) blocker, whereas these TGF- $\beta$-blockers had no effect on Th17 cells. Addition of an interleukin (IL)-2 blocker reduced the proportion of Th17 cells when co-cultured with a high number of MSCs compared with the low concentration group and the proportion of Treg cells was significantly decreased when cells were treated with an IL-2 blocker compared with the control group. Together, these results showed the varying effects of MSCs on the ratio of Treg/Th17, its dependence on the number of MSCs and the effects of cytokines in inducing these changes in the balance.
\end{abstract}

Correspondence to: Dr Wei Gao, Department of Transplant Surgery, Tianjin First Central Hospital, 24 Fukang Road, Tianjin 300192, P.R. China

E-mail: gao-wei@medmail.com.cn

*Contributed equally

Key words: mesenchymal stem cells, regulatory T cells, Th17 cells, cytokines

\section{Introduction}

Mesenchymal stem cells (MSCs) are a group of multipotent cells that can mature into cells with various immunomodulatory functions. Additionally, MSCs exert regulatory effects on the maturation and differentiation of immune cells, such as naive T cells and dendritic cells. They also exert effects on the secretion of different cytokines and the expression of surface receptors in these immune cells (1). During the differentiation process of naive $\mathrm{T}$ cells, there are two types of cells that have gained increasing attention in recent years: Regulatory T cells (Tregs) that inhibit the inflammatory immune response, and $\mathrm{T}$ helper 17 (Th17) cells that exert a proinflammatory effect and secrete various inflammatory cytokines, including interleukin (IL)-17, IL-6 (2). Özdemir et al (3) reported that MSCs can promote the proliferation and transformation of Treg cells and inhibit the proliferation of Th17 cells. A shift in the immune balance between Treg/Th17 cells towards Treg cells can result in an escape from the immune response from the host, and it can help to maintain homeostasis and induce immune tolerance (4).

In an animal study on liver transplantation, the postoperative survival time and liver function of rats that were treated with tacrolimus + MSCs were improved compared with the rats treated with a standard dose of tacrolimus alone (5). MSCs can inhibit Th1 and Th17 cells, promote the expression of anti-inflammatory cytokines in Th2 cells (6) and induce the differentiation of immature T cells into Treg cells (7). A shift in the Treg/Th17 balance towards Th17 cells and increased IL-17 production may underlie graft rejection (8). Therefore, the effects of MSCs on the Treg/Th17 balance is of notable interest to potentially increase tissue acceptance in transplant surgeries. However, the mechanism by which MSCs regulate Treg/Th17 balance and its function on immunosuppression are still unclear.

In the present study, co-cultures of different quantities of bone marrow derived (BM)-MSCs and $\mathrm{CD}^{+} \mathrm{T}$ lymphocytes were used to investigate the effect of BM-MSCs on the balance of Treg/Th17 under various conditions via the addition of different immunosuppressive agents and cytokine blockers. The aim of the present study was to provide an experimental basis for the use of MSCs in certain clinical conditions. 


\section{Materials and methods}

Animals. Male Wistar rats $(\mathrm{n}=18$; age, 3 weeks; weight, 50-55 g) were used for isolation of MSCs for culture. Male Wistar rats ( $\mathrm{n}=12$; age, 6 weeks; weight, 180-210 g) were used for isolation of $\mathrm{CD}^{+}{ }^{+} \mathrm{T}$ lymphocytes. Rats were obtained from the experimental animal center of the Chinese Academy of Military Medical Sciences (license no. SCXK). Animals were housed in a pathogen-free environment at $20-25^{\circ} \mathrm{C}$ with $50-70 \%$ humidity, ad libitum access to food and water, and 12-h light/dark cycles. The present study was approved by the Ethics Committee of Tianjin First Center Hospital (Tianjin, China) and was performed in accordance with the principles of 3Rs and those described in the Experimental Animal Welfare Ethics Review Guide of China (GB/T 35892-2018).

Materials. Foxp3 transcription factor staining buffer kit, IL-17 intracellular staining buffer kit, monoclonal antibodies against CD4, CD25, Foxp3 and IL-17, rat anti- transforming growth factor- $\beta$ (TGF- $\beta$ ) antibody, and ProcartaPlex ${ }^{\mathrm{TM}}$ cytokine detection kits for IL-6, IL-10, IL-17 and TGF- $\beta$ were all purchased from eBioscience; Thermo Fisher Scientific, Inc. Mouse anti-IL-2 antibody and monoclonal antibodies against CD29, CD45 and CD90 were purchased from Becton, Dickinson and Company. Rat CD4 ${ }^{+}$T lymphocyte magnetic beads, MS sorting column and magnetic cell sorter were purchased from (Miltenyi Biotec GmbH). All samples were tested on a FACSCanto ${ }^{\mathrm{TM}}$ II flow cytometer (Becton, Dickinson and Company).

Extraction, culture and identification of BM-MSCs. Bone marrow cell suspension was obtained from the femur of a $50 \mathrm{~g}$ male Wistar rat. Male Wistar rats were sacrificed by cervical dislocation and sterilized in $75 \%$ ethanol for $10 \mathrm{~min}$ at room temperature. Subsequently, the femur and tibia were obtained by aseptic operation. After the bone marrow cavity was exposed, the bone marrow cell suspension was obtained by rinsing the marrow cavity four times with DMEM/F12 complete culture medium (Gibco; Thermo Fisher Scientific, Inc.). The cells were cultured in DMEM/F12 medium with $5 \% \mathrm{CO}_{2}$ at $37^{\circ} \mathrm{C}$ with $100 \%$ humidity. Anti-CD29 (cat. no. 562801), anti-CD45 (cat. no. 561588) and anti-CD90 (cat. no. 561409) antibodies were used to label the cells, and the purity of BM-MSCs cells was assessed by flow cytometry using Flow Jo software (version 7.6.1; Flow Jo LLC). The average ratio of $\mathrm{CD} 90^{+}, \mathrm{CD} 29^{+}$and $\mathrm{CD} 45^{+}$ BM-MSCs were $99.83 \pm 0.01,97.50 \pm 0.10$ and $4.06 \pm 0.47 \%$, respectively. The number of extracted $\mathrm{CD} 4^{+} \mathrm{T}$ lymphocytes was $\sim 5.7 \pm 0.3 \times 10^{6} / \mathrm{ml}$ and the purity was $>95 \%$, which was considered satisfactory for all subsequent experiments.

Extraction of $\mathrm{CD}^{+}$T lymphocytes. A suspension of mononuclear cells was obtained from the grinded spleen of Wistar rats by Ficoll-Hypaque density gradient centrifugation at $838 \mathrm{x} \mathrm{g}$ for $25 \mathrm{~min}$ at room temperature and then at $503 \mathrm{x} \mathrm{g}$ for $15 \mathrm{~min}$ at room temperature. Subsequently, the supernatant was discarded and $\mathrm{CD}^{+} \mathrm{T}$ lymphocyte magnetic beads were added. After thoroughly mixing and incubating at $4^{\circ} \mathrm{C}$ for $15 \mathrm{~min}$, the cell suspension was extracted using an MS sorting column and a magnetic cell sorter. Subsequently, CD $4^{+} \mathrm{T}$ lymphocytes were obtained and the purity was measured by flow cytometry.
Co-culture of BM-MSCs with CD $4^{+} T$ lymphocytes. The BM-MSCs were plated into a 6-well plate at a density of $1 \times 10^{5}$ cells/well $(0.5 \times \mathrm{xr}), 2 \times 10^{5}$ cells/well $(1 \times \mathrm{xG}), 4 \times 10^{5}$ cells $/$ well ( $2 \times \mathrm{Gr}$ ) or $8 \times 10^{5}$ cells/well $(4 \mathrm{xGr})$. The extracted $\mathrm{CD}^{+} \mathrm{T}$ lymphocytes were added to the culture plates with the BM-MSCs and $5 \mathrm{mg} / \mathrm{ml}$ of PHA and $50 \mu \mathrm{g} / \mathrm{ml}$ of IL- 2 was added. After $72 \mathrm{~h}$, the culture medium was collected, centrifuged at $503 \mathrm{x} \mathrm{g}$ for $10 \mathrm{~min}$ at room temperature, and the supernatant was collected and stored at $-80^{\circ} \mathrm{C}$. The residual cells were incubated with anti-CD4 (cat. no. 11-0040-82) and anti-CD25 (cat. no. 46-0390-82) for $60 \mathrm{~min}$ at room temperature, and anti-Foxp3 (cat. no. 12-5773-82) and anti-IL-17A (cat. no. 12-7177-81) for $30 \mathrm{~min}$ at room temperature. Subsequently, cells were analyzed by flow cytometry (Figs. S1 and S2).

Immunosuppressant treatment. Tacrolimus (8 or $12 \mathrm{ng} / \mathrm{ml}$ ) or rapamycin (100 or $150 \mathrm{nmol} / \mathrm{l}$ ) were used as immunosuppressants and added to the co-cultures of BM-MSCs and CD4 ${ }^{+}$ $\mathrm{T}$ lymphocytes and incubated for $72 \mathrm{~h}$. The supernatant was stored at $-80^{\circ} \mathrm{C}$ for assessment of the presence of cytokines and the cells were analyzed using flow cytometry.

Cytokine inhibitors. BM-MSCs were co-cultured with $\mathrm{CD}^{+} \mathrm{T}$ lymphocytes as described above and treated with varying concentrations of TGF- $\beta$ inhibitors (10 or $20 \mu \mathrm{g} / \mathrm{ml}$ ) or different concentrations of IL-2 inhibitors ( 2 or $4 \mu \mathrm{g} / \mathrm{ml}$ ). Treated co-cultured cells were incubated for $72 \mathrm{~h}$. The supernatant was collected after centrifugation at $503 \mathrm{x}$ g for $10 \mathrm{~min}$ at $4^{\circ} \mathrm{C}$ and stored at $-80^{\circ} \mathrm{C}$ refrigerator to measure levels of cytokines. The proportions of Treg and Th17 cells were analyzed using flow cytometry. The TGF- $\beta$ blocker used was anti-TGF- $\beta$ functional grade purified (cat. no. 16-9243-85; eBioscience; Thermo Fisher Scientific, Inc.) and IL-2 blocker used was purified mouse anti-rat CD25 (cat. no. 559980; Becton, Dickinson and Company; Thermo Fisher Scientific, Inc.). The dosage of TGF- $\beta$ used was $20 \mu \mathrm{g} / \mathrm{ml}$ in the higher concentration group and $10 \mu \mathrm{g} / \mathrm{ml}$ in the lower concentration group, respectively. The dosage of IL-2 was $4 \mu \mathrm{g} / \mathrm{ml}$ in the higher concentration group and $2 \mu \mathrm{g} / \mathrm{ml}$ in the lower concentration group.

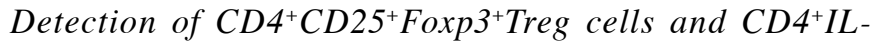
$17^{+}$Th17 cells. The collected cells were tested by immunophenotyping for surface or intracellular markers with monoclonal antibodies specific for each protein.

Measurement of expression of cytokines. The concentration of IL-6, IL-10, IL-17 and TGF- $\beta$ were measured. After diluting the antibody magnetic beads 1:50, $50 \mu \mathrm{l}$ of the sample was added to each well in a 96-well plate and the plate was placed on a magnetic rack. After 2 min, the supernatant was discarded and washed with wash buffer once. Additional care was taken not to detach the 96-well plate from the magnetic plate rack during the process to prevent the magnetic beads from falling off. The provided reagents in each kit were dissolved according to the manufacturer's protocol and different dilutions were added to the 96-well plates. DMEM/F12 complete medium was added to the final well as the blank control group. Experiments where performed with 6 repeats per each condition and 2 groups were used to plot the standard curve. A total of $50 \mu 1$ of sample 
was added to the remaining wells and $25 \mu \mathrm{l}$ of wash buffer was added to these wells. The plate was incubated for $2 \mathrm{~h}$ at room temperature to allow the magnetic beads to bind to the corresponding cytokines. After incubation, the wells were washed with the special solution three times and $25 \mu \mathrm{l}$ of a diluted solution of the corresponding cytokine antibody was added, incubated at room temperature in the dark for $30 \mathrm{~min}$, rinsed with special solution, $50 \mu \mathrm{l}$ of phycoerythrin dye was added and incubated on an oscillator for $30 \mathrm{~min}$ at room temperature. After the incubation, the buffer was cleaned once with the special solution and $120 \mu 1$ reading buffer was added to each well. The buffer was placed on the oscillator for $5 \mathrm{~min}$ to ensure the solution was adequately mixed prior to taking measurements.

Statistical analysis. For normally distributed data, data are expressed as the mean \pm standard deviation. For non-normally distributed data, data are expressed as the median and interquartile range (Q25 and Q75). One-way ANOVA followed by Tukey's post hoc test was used for comparison of multiple groups if the data were normally distributed. Kruskal-Wallis test followed by Dunn's post hoc test was performed to assess comparisons among multiple groups if the data were not normally distributed. $\mathrm{P}<0.05$ was considered to indicate a statistically significant difference. Statistical analyses were performed using SPSS version 19.0 (IBM, Corp.).

\section{Results}

Effects of BM-MSCs on the Treg/Th17 balance. There was a significant difference in the proportion of Treg cells amongst the co-cultures with different numbers of BM-MSCs added $(\mathrm{P}=0.001$; Fig. 1). Amongst these, $2 \mathrm{xGr}$ had the highest proportion of Treg cells $(9.24 \pm 2.68 \%)$, which was significantly increased compared with $0.5 \times \mathrm{xr}(3.87 \pm 0.38 \%, \mathrm{P}=0.002), 1 \times \mathrm{Gr}$ $(5.16 \pm 1.69 \%, \mathrm{P}=0.017)$ and $4 x \mathrm{Gr}(3.86 \pm 0.36 \%, \mathrm{P}=0.002)$. The differences in the proportion of Treg cells in the other three groups were not statistically significant $(\mathrm{P}>0.05)$. The proportion of Th17 cells was significantly different amongst the co-cultures with different numbers of BM-MSCs added $(\mathrm{P}<0.001)$. The proportion of Th17 cells in the $1 \mathrm{xGr}$ $(0.89 \pm 0.08 \%)$ was the highest and was significantly increased compared with $0.5 \times \mathrm{Gr}(0.64 \pm 0.15 \%, \mathrm{P}=0.020)$ and $4 \mathrm{xGr}$ $(0.37 \pm 0.10 \%, \mathrm{P}<0.001)$, but there was no significant difference compared with $2 \times \mathrm{Xr}(0.83 \pm 0.06 \%, \mathrm{P}=0.796)$. The proportion of Th17 cells in the $0.5 x \mathrm{Gr}$ was not reduced compared with $2 \mathrm{xGr}$ $(\mathrm{P}=0.095)$, but was increased compared with $4 \times \mathrm{Gr}(\mathrm{P}=0.013)$.

There were statistically significant differences in IL-10 levels between the groups $(\mathrm{P}=0.021)$. IL-10 levels in $0.5 \mathrm{xGr}$ was significantly lower compared with the other groups $(\mathrm{P}<0.05)$, except $4 \mathrm{xGr}(\mathrm{P}=0.111)$, although no statistical difference was observed in comparisons between the other groups. TGF- $\beta$ levels were also significantly different amongst the groups $(\mathrm{P}=0.041)$. The level of TGF- $\beta$ in $0.5 \mathrm{xGr}$ was lower compared with $1 \mathrm{xGr}(\mathrm{P}=0.044)$. TGF- $\beta$ levels were the lowest in $4 \mathrm{xGr}$, but the difference was only significant when compared with $1 \times \mathrm{Gr}(\mathrm{P}=0.037)$. IL-6 and IL-17 were not detected in $0.5 \mathrm{xGr}$, and there was no significant difference observed between the levels of these cytokines in any of the groups $(\mathrm{P}=0.385$ and $\mathrm{P}=0.997$, respectively).
Effect of different immunosuppressants on BM-MSC-mediated regulation of the Treg/Th17 balance. In the high tacrolimus concentration group, low tacrolimus concentration group and control group, the median proportions of Treg cells were $1.83 \%(1.36$ and $2.50 \%), 2.98 \%$ (2.36 and 3.18\%) and $10.45 \%$ (6.48 and $10.78 \%)$, respectively, and there was a statistically significant difference amongst the three groups $(\mathrm{P}=0.010)$. As shown in Fig. 2, the median proportions of Th17 cells in the high tacrolimus concentration group, low tacrolimus concentration group and the blank control group was $1.30 \%(0.76$ and $1.56 \%), 1.06 \%(0.69$ and $1.16 \%)$ and $0.80 \%(0.79$ and $0.89 \%)$, respectively, and there was no significant difference amongst the three groups $(\mathrm{P}=0.333)$.

The levels of IL-10 in the high tacrolimus concentration group, low tacrolimus concentration group and blank control group were not significantly different $(\mathrm{P}=0.058)$, but the differences in the levels of TGF- $\beta$ were statistically significant $(\mathrm{P}=0.035)$. TGF- $\beta$ levels in the high and low tacrolimus concentration group were lower compared with the blank control group $(\mathrm{P}=0.020$ and $\mathrm{P}=0.028$, respectively), the difference between the high and low concentration groups was not significant $(\mathrm{P}=0.835)$. The levels of IL-6 and IL-17 in the high and low tacrolimus concentration group and the blank control group was statistically significant $(\mathrm{P}=0.001$ and $\mathrm{P}=0.024$, respectively). In both the high and low tacrolimus concentration groups, IL-6 levels were significantly increased compared with the blank control group $(\mathrm{P}<0.05)$. IL-17 levels in the high and low tacrolimus concentration groups were both significantly decreased compared with the blank control group $(\mathrm{P}<0.05)$, and the difference between the high and low concentration group was not significant $(\mathrm{P}=0.241$ and $\mathrm{P}=0.845)$.

The proportion of Treg cells in the high rapamycin concentration group, low rapamycin concentration group and the blank control group was $4.29 \pm 0.77,3.98 \pm 0.64$ and $2.68 \pm 0.44 \%$, respectively, and the differences between the three groups were statistically significant $(\mathrm{P}=0.013)$. The median proportions of Th17 cells in the high rapamycin concentration group, low rapamycin concentration group and the blank control group was $0.624 \%$ (0.570 and $0.721 \%), 0.505 \%$ (0.320 and $0.756 \%)$ and $0.799 \%$ (0.792 and $0.890 \%)$, respectively, and the differences between the three groups were statistically significant $(\mathrm{P}=0.037)$.

The differences amongst the IL-10 levels in the high rapamycin concentration group, low rapamycin concentration group and the blank control group was statistically significant $(\mathrm{P}<0.001)$. IL-10 levels in the high and low rapamycin concentration groups were lower compared with the blank control group (both $\mathrm{P}<0.001$ ), but the difference between the high concentration and low concentration groups were not statistically significant $(\mathrm{P}=0.342)$. There was no statistically significant difference in the TGF- $\beta$ levels amongst the three groups $(\mathrm{P}=0.218)$, but the difference in the level of IL-6 was significant $(\mathrm{P}=0.024)$. IL-6 levels in the high and low concentration rapamycin groups were lower compared with the blank control group $(\mathrm{P}=0.027$ and $\mathrm{P}=0.012$, respectively), but the difference between the high and low concentration groups was not statistically significant $(\mathrm{P}=0.768)$.

The Treg/Th17 balance regulated by BM-MSCs when treated with tacrolimus or rapamycin showed that both the 

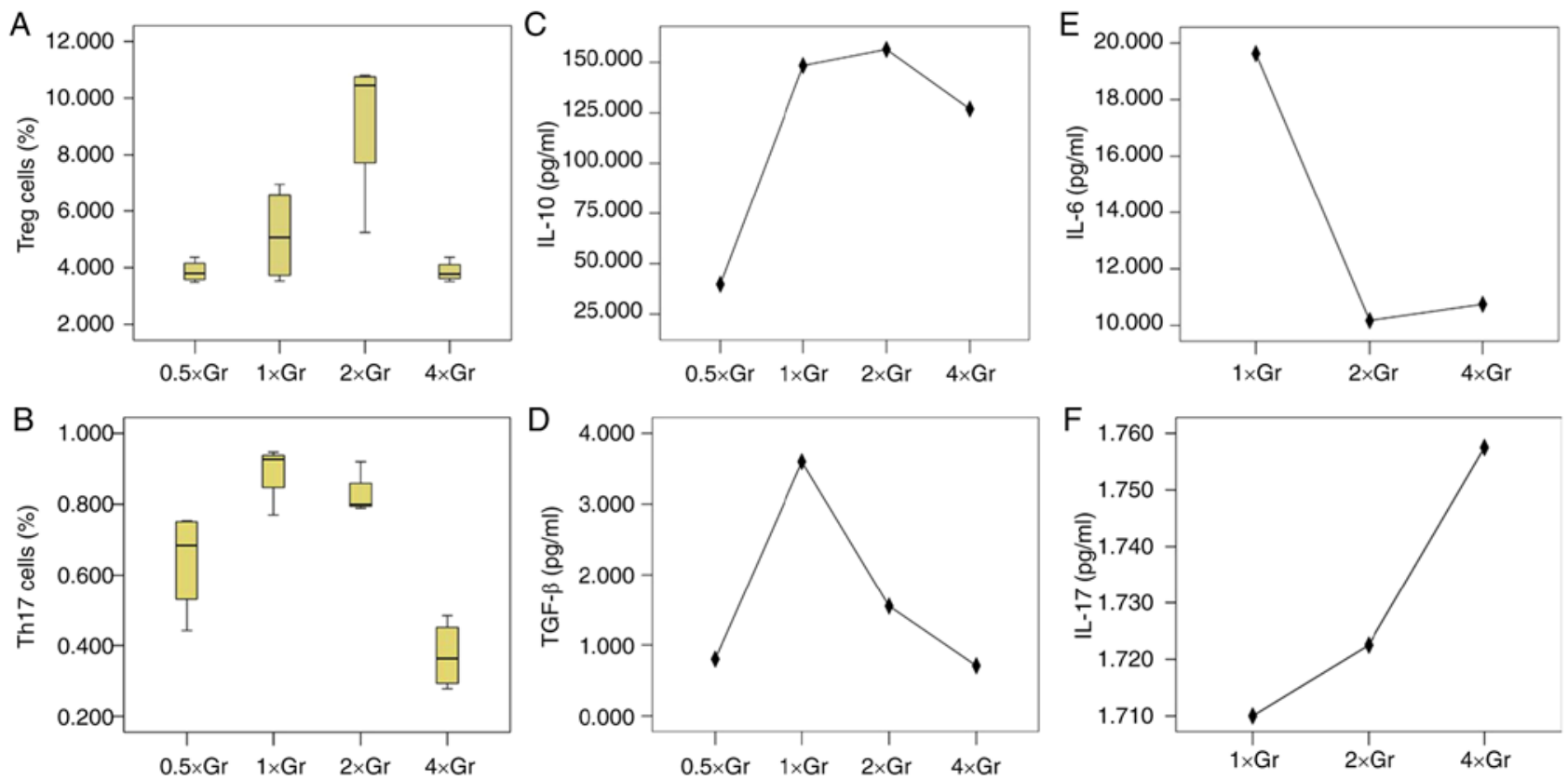

Figure 1. Treg/Th17 cells and cytokines in different concentrations of BM-MSCs co-cultured with CD4+ T lymphocytes. (A) Proportions of Treg cells in each group, which showed that BM-MSCs in 2xGr had the strongest effect on promoting proliferation of Treg cells. (B) Proportions of Th17 cells in each group, in which the proportion of $1 x \mathrm{Xr}$ was the highest and the proportion of $4 \mathrm{xGr}$ was the lowest. Levels of: (C) IL-10, P=0.021; (D) TGF- $\beta$, P=0.041; (E) IL-6, $\mathrm{P}=0.995$; and (F) IL-17, P=0.760. Treg, regulatory T; Th17, T helper 17; BM-MSCs, bone marrow mesenchymal stem cells; IL, interleukin; TGF, transforming growth factor.

proportions of Treg/Th17 cells and their associated cytokines, excluding TGF- $\beta$, were statistically different as shown in Tables I and II. The proportion of Treg cells in co-cultures treated with rapamycin treatment were higher compared with the tacrolimus group, whereas the proportion of Th17 cells, IL-10 and IL-6 levels were lower compared with the tacrolimus group.

Effect of TGF- $\beta$ blocker on BM-MSC mediated regulation of the Treg/Th17 balance. The proportion of Treg cells in the high concentration of TGF- $\beta$ blocker, low concentration of TGF- $\beta$ blocker and blank control groups were $2.81 \pm 0.38,4.23 \pm 0.97$ and $9.24 \pm 2.68 \%$, respectively, and there was a statistically significant difference amongst the three groups $(\mathrm{P}=0.001)$. The proportion of Th17 cells in the high concentration, low concentration and blank control groups were $0.85 \pm 0.20,0.83 \pm 0.14$ and $0.83 \pm 0.06 \%$, respectively, and the difference amongst the three groups was not statistically significant ( $\mathrm{P}=0.976$; Fig. 3).

The levels of IL-10 in the high concentration blocking group, low concentration blocking group and the blank control group was significantly different $(\mathrm{P}<0.001)$. However, there was no significant difference in TGF- $\beta$ levels amongst the three groups. IL-6 levels in the low concentration blocking group and the high concentration blocking group were significantly lower compared with the control group $(\mathrm{P}<0.001)$, and the difference between the high concentration blocking group and the low concentration blocking group was not significant $(\mathrm{P}=0.062)$. The differences in the levels of IL-17 amongst the three groups was not significant.

Effect of IL-2 blocker on BM-MSC mediated regulation of the Treg/Th17 balance. The proportions of Treg cells in the high concentration blocking group, low concentration blocking group and blank control groups was $1.95 \pm 2.21,1.66 \pm 1.51$ and $9.24 \pm 2.68 \%$, respectively, and the differences between the three groups was significant $(\mathrm{P}=0.001)$. The proportions of Th17 cells in the three groups were $0.74 \pm 0.16,0.99 \pm 0.05$ and $0.83 \pm 0.06 \%$, respectively and the difference between the groups was significant ( $\mathrm{P}=0.022$; Fig. 4).

The levels of IL-10 in the three groups were significantly different. The IL-10 levels in the low concentration blocking group was lower compared with the control group $(\mathrm{P}=0.005)$ and no significant difference was observed when compared with the high concentration blocking group $(\mathrm{P}=0.350)$. There was no significant difference in the TGF- $\beta$ levels amongst the three groups. IL-6 in the high concentration blocking group was significantly higher compared with the control group $(\mathrm{P}=0.008)$, but was not significantly different compared with the low concentration blocking group $(\mathrm{P}=0.202)$. IL-17 levels were significantly different in the high concentration blocking group, low concentration blocking group and the blank control group, with IL-17 levels being lower in the high and low concentration groups compared with the control group $(\mathrm{P}=0.031$ and $\mathrm{P}=0.024$, respectively), but the difference between the high and low concentration groups was not significant $(\mathrm{P}=0.922)$.

\section{Discussion}

Previous studies have reported that the effect of MSCs on the Treg/Th17 balance primarily results in promotion of the proliferation and transformation of Treg cells, inhibition of the proliferation of Th17 cells and secretion of cytokines $(9,10)$. Liu et al (9) demonstrated that BM-MSCs significantly increased the proportion of Treg cells, induced the differentiation of $\mathrm{CD} 4{ }^{+} \mathrm{CD} 25^{-}$cells into Treg cells and increased the expression of Foxp3 in a co-culture of BM-MSCs and T cells 
A
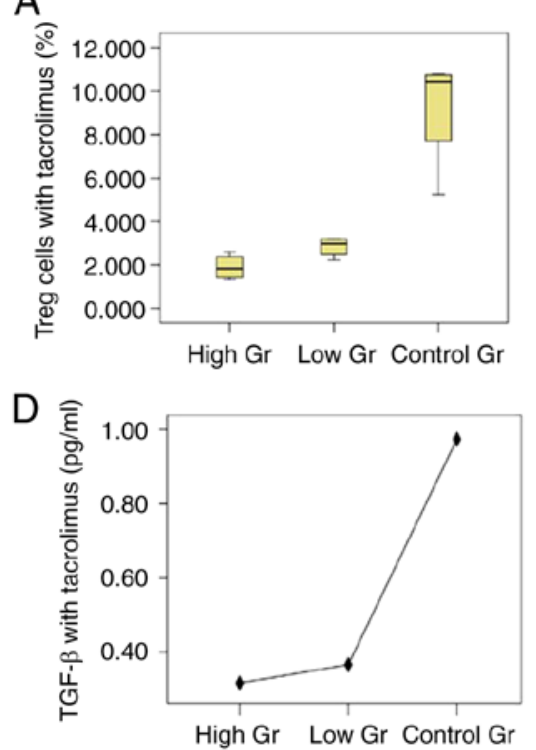

$\mathrm{G}$

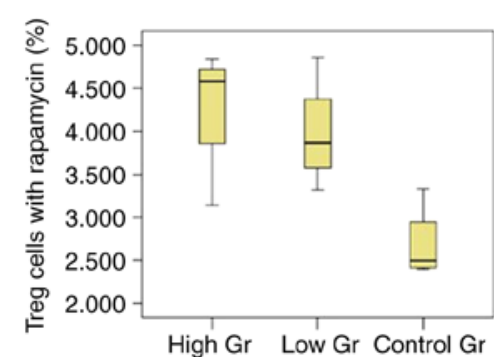

$\mathrm{B}$

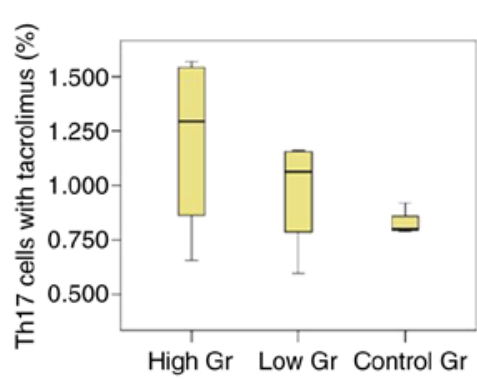

$\mathrm{E}$

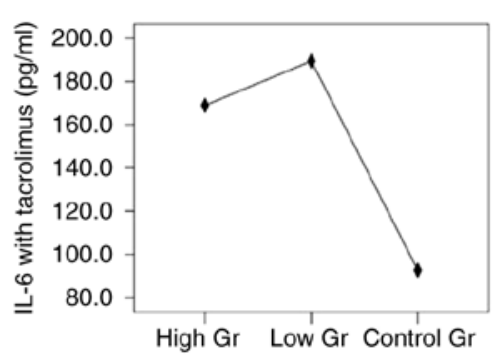

$\mathrm{H}$

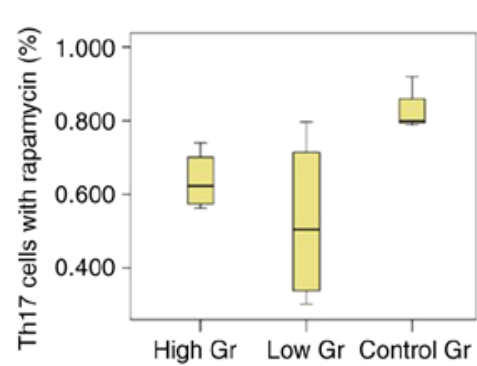

C
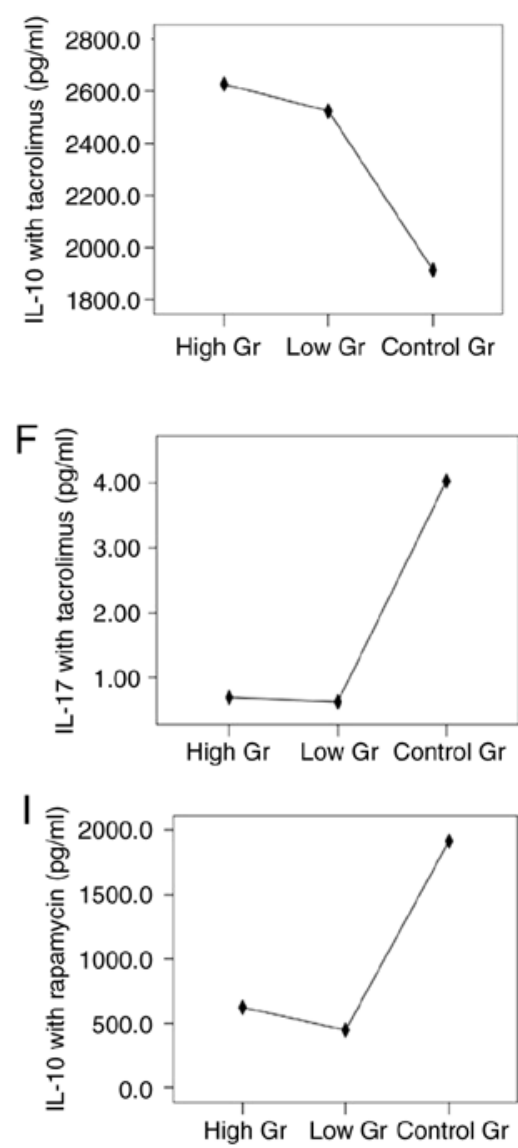
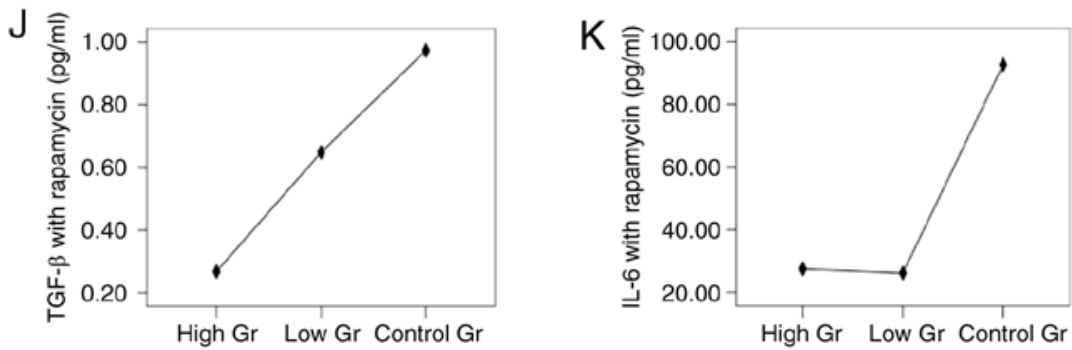

Figure 2. Treg/Th17 cells and cytokines co-cultured by BM-MSCs and CD4 ${ }^{+} \mathrm{T}$ lymphocytes with different immunosuppressive agents. Proportions of cultured (A) Treg cells and (B) Th17 cells under the action of tacrolimus, respectively. The proportion of Treg cells in the high tacrolimus group and the low tacrolimus group were lower compared with the control group $(\mathrm{P}=0.016$ and $\mathrm{P}=0.018$, respectively), but there was no statistical difference between the high and low group $(\mathrm{P}=0.055)$. The proportions of Th17 cells show no significant difference $(\mathrm{P}=0.333)$. Expression of (C) IL-10 ( $\mathrm{P}=0.058)$, (D) TGF- $\beta$ ( $\mathrm{P}=0.035)$, (E) IL-6 $(\mathrm{P}=0.001)$ and $(\mathrm{F}) \mathrm{IL}-17(\mathrm{P}=0.024)$ under the action of tacrolimus, respectively. Proportions of $(\mathrm{G})$ Treg cells and $(\mathrm{H})$ Th17 cells under the action of rapamycin, respectively. The proportions of Treg cells in high and low rapamycin concentration groups were higher than that in the blank control group $(\mathrm{P}=0.006$, $\mathrm{P}=0.018)$ respectively, but the difference between the high and low concentration groups was not statistically significant $(\mathrm{P}=0.507)$. The proportions of Th17 cells in the group with high and low concentrations of rapamycin were lower than that in the blank control group ( $\mathrm{P}=0.039$, $\mathrm{P}=0.018)$, but the difference between the groups with high and low concentrations was not statistically significant $(\mathrm{P}=0.768)$. Levels of (I) IL-10 ( $\mathrm{P}<0.001),(\mathrm{J})$ TGF- $\beta$ ( $\mathrm{P}=0.218)$ and (K) IL-6 ( $\mathrm{P}=0.024)$ with rapamycin treatment, respectively. IL-17 wasn't detected in the rapamycin groups. Treg, regulatory T; Th17, T helper 17; BM-MSCs, bone marrow mesenchymal stem cells; IL, interleukin; TGF, transforming growth factor.

in vitro. A decrease in the number of Th17 cells was also observed in the co-culture of MSCs and T cells in rats (10). However, Rozenberg et al (11) found that MSCs promoted the response of Th17 cells and increased the proportion of Th17 cells in a co-culture of human MSCs and peripheral blood monocytes.

MSCs regulate the Treg/Th17 balance through various mechanisms. MSCs can induce the differentiation of $\mathrm{CD}^{+}{ }^{+} \mathrm{T}$ lymphocytes into $\mathrm{CD} 4^{+} \mathrm{CD} 25^{+} \mathrm{Foxp} 3^{+}$Treg cells via toll-like receptors and the MSC-mediated increase in proliferation was absent when toll-like receptor genes were knocked out (12). In the inflammatory environment in vivo, MSCs exert their inhibitory function on $\mathrm{T}$ cell activation and proliferation via the secretion of IL-10, hemagglutinin-1 and anti-inflammatory cytokines (13). In addition, MSCs can also promote the proliferation and differentiation of Treg cells by secreting anti-inflammatory cytokines, such as TGF- $\beta$ and prostaglandin (14). The proportion of Th17 cells is decreased by blocking the IL-10 signaling pathways, which is possible via inhibition of cytokine signaling 3 , signal transduction and transcriptional activation factor 3 and retinoid-related orphan nuclear receptor (15). 
Table I. Treg/Th17 balance under high concentration of immunosuppressants.

\begin{tabular}{lccr}
\hline Subject & Tacrolimus Gr & Rapamycin Gr & P-value \\
\hline Treg cells $(\%)$ & $1.90 \pm 0.60$ & $4.29 \pm 0.77$ & 0.003 \\
Th17 $(\%)$ & $1.30(0.76,1.56)$ & $0.62(0.57,0.72)$ & 0.043 \\
IL-10 $(\mathrm{pg} / \mathrm{ml})$ & $2,560.865(2,158.730,3,163.318)$ & $683.775(464.335,726.020)$ & 0.021 \\
TGF- $\beta(\mathrm{pg} / \mathrm{ml})$ & $0.316 \pm 0.283$ & $0.267 \pm 0.195$ & 0.786 \\
IL-6 $(\mathrm{pg} / \mathrm{ml})$ & $167.745(140.938,198.168)$ & $27.640(23.063,31.648)$ & 0.021
\end{tabular}

Treg, regulatory T; Th17, T helper 17; IL, interleukin; TGF, transforming growth factor.

Table II. Treg/Th17 balance under low concentration of immunosuppressants.

\begin{tabular}{lccr}
\hline Subject & Tacrolimus Gr & Rapamycin Gr & P-value \\
\hline Treg cells $(\%)$ & $2.84 \pm 0.45$ & $3.98 \pm 0.64$ & 0.027 \\
Th17 cells $(\%)$ & $0.97 \pm 0.26$ & $0.53 \pm 0.23$ & 0.044 \\
IL-10 $(\mathrm{pg} / \mathrm{ml})$ & $2,524.180 \pm 448.853$ & $448.853 \pm 148.364$ & $<0.001$ \\
TGF- $\beta(\mathrm{pg} / \mathrm{ml})$ & $0.366 \pm 0.301$ & $0.648 \pm 0.798$ & 0.533 \\
IL-6 $(\mathrm{pg} / \mathrm{ml})$ & $191.925(168.505,207.763)$ & $24.590(20.583,33.180)$ & 0.021 \\
\hline
\end{tabular}

Treg, regulatory T; Th17, T helper 17; IL, interleukin; TGF, transforming growth factor.
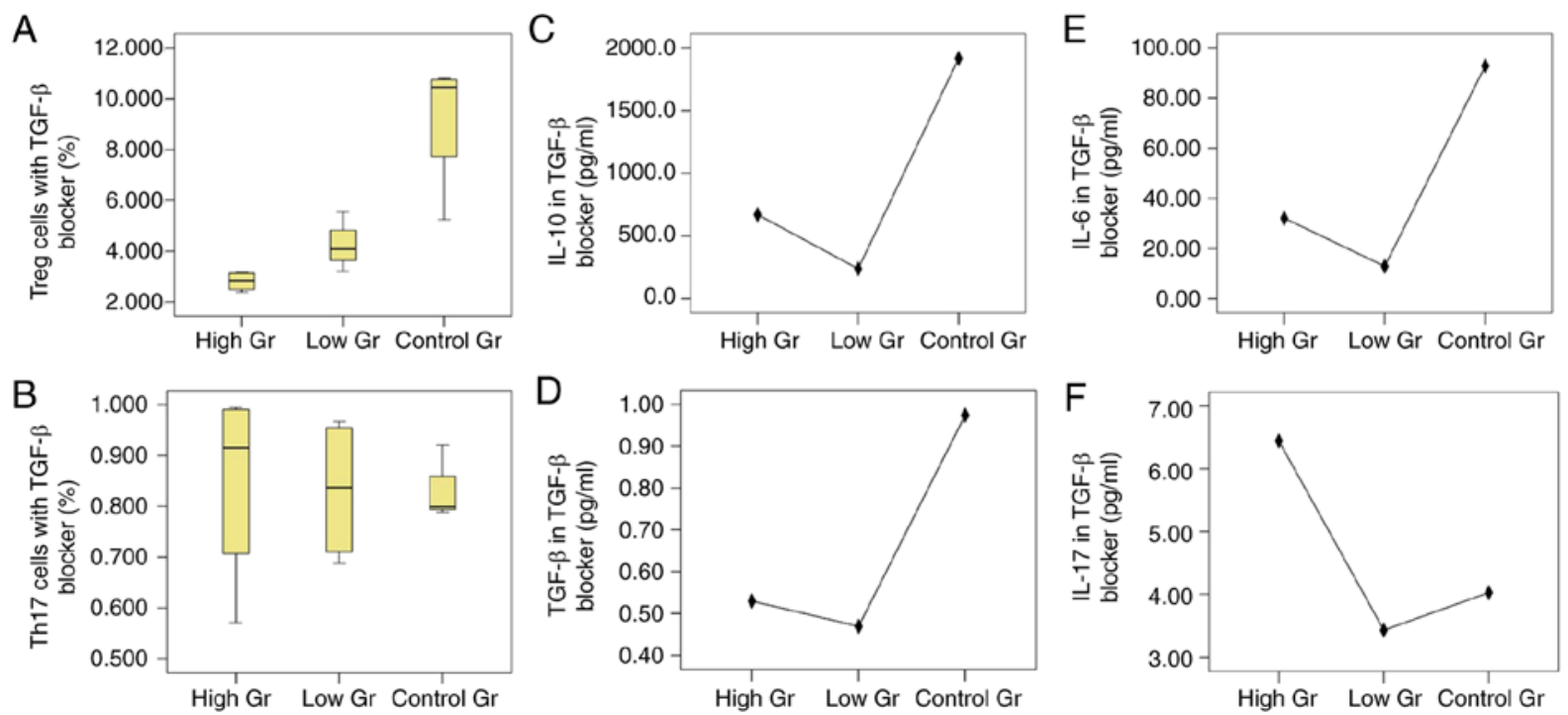

Figure 3. Proportions of Treg/Th17 cells and cytokines after co-culture of BM-MSCs and CD4 ${ }^{+} \mathrm{T}$ lymphocytes after blocking TGF- $\beta$. Proportions of (A) Treg and (B) Th17 cells after TGF- $\beta$ blocker treatment. The proportion of Treg cells in the blocking groups were lower than that in the blank control group $(\mathrm{P}=0.001)$, but there was no difference in the proportions of Treg cells between the groups with different doses of blocking agents $(\mathrm{P}=0.476)$. There was no statistical difference in the proportions of Th17 cells among the three groups ( $\mathrm{P}=0.976)$. Expression of (C) IL-10 (P<0.001), (D) TGF- $\beta$ ( $P=0.263$ ), (E) IL-6 $(\mathrm{P}=0.000)$ and $(\mathrm{F}) \mathrm{IL}-17(\mathrm{P}=0.172)$ in TGF- $\beta$ blocking groups at different concentrations, respectively. Treg, regulatory T; Th17, T helper 17; BM-MSCs, bone marrow mesenchymal stem cells; IL-, interleukin; TGF, transforming growth factor.

In the present study, it was demonstrated that the concentration of BM-MSCs had a significant influence on the Treg/Th17 balance, where BM-MSCs were able shift the balance towards both cell types dependent on the concentration of BM-MSCs added, but there was no positive association between the concentration of BM-MSCs and the proportion of Treg/Th17 cells. When the concentration of BM-MSCs in the co-culture was high, the proportions of Treg cells and Th17 cells were significantly decreased. However, changes to the levels of relevant cytokines were not observed and did not appear to be associated with changes to the proportions of Treg/Th17 cells, and this may be due to secretion of TGF- $\beta$ and IL-10 by MSCs.

The most commonly used immunosuppressants include calcineurin inhibitors and mTOR, and they exert different 
A
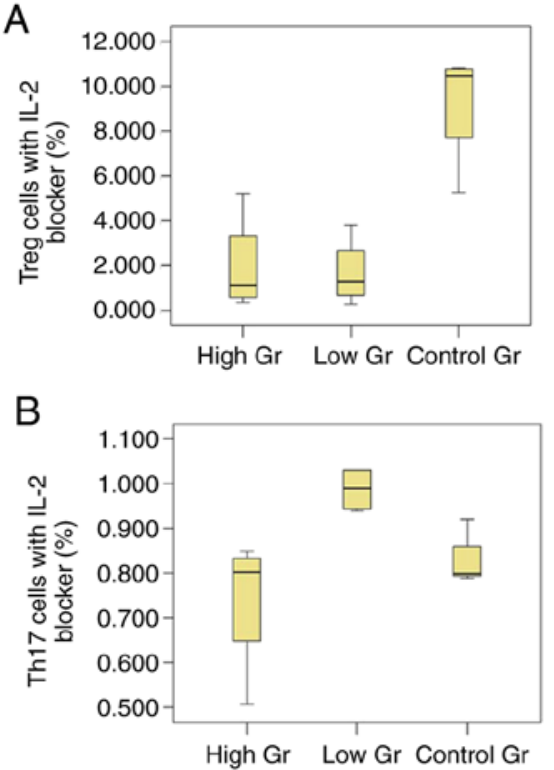

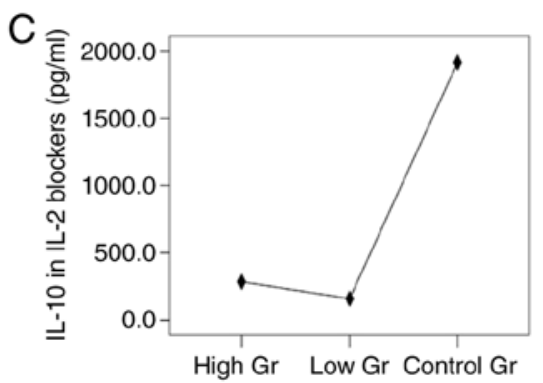

D

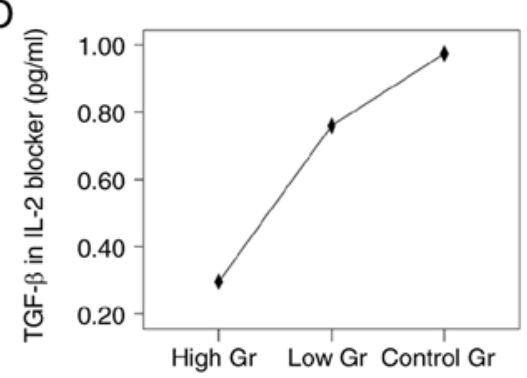

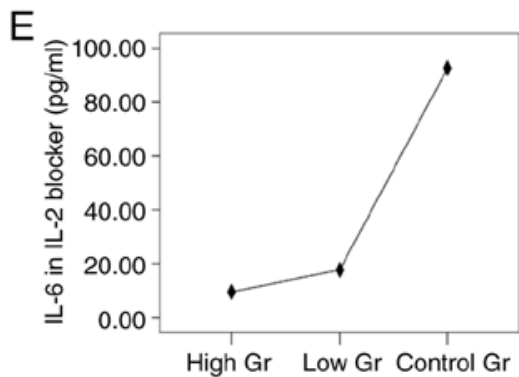

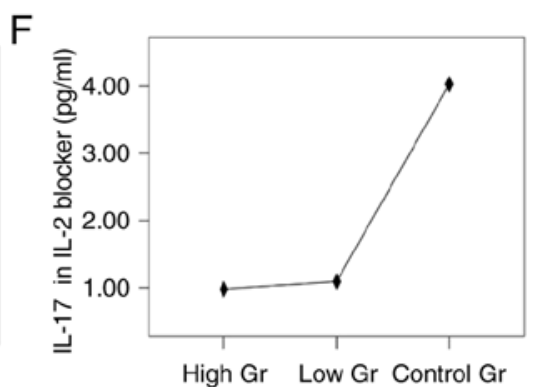

Figure 4. Proportions of Treg/Th17 cells and cytokines after co-culture of BM-MSCs and CD4+ T lymphocytes after blocking IL-2. Proportions of (A) Treg cells and (B) Th17 cells under the action of an IL-2 blocker. The proportions of Treg cells in the high and low concentration blocking groups were both lower than that in the blank control group $(\mathrm{P}=0.003, \mathrm{P}=0.002)$, but there was no difference in the proportions of Treg cells between the groups with different concentrations of blocking agents $(\mathrm{P}=0.981)$. The proportion of Th17 cells in the high concentration blocking group was lower than that in the low concentration blocking group $(\mathrm{P}=0.019)$, however compared with the blank control group the difference was not significant $(\mathrm{P}=0.482)$. There was no difference between the low concentration blocking group and the control group ( $\mathrm{P}=0.054)$. Expression of (C) IL-10 (P=0.007), (D) TGF- $\beta$ (P=0.059), (E) IL-6 (P=0.011) and (F) IL-17 $(\mathrm{P}=0.039)$ of IL-2 blocking groups at different concentrations, respectively. Treg, regulatory T; Th17, T helper 17; BM-MSCs, bone marrow mesenchymal stem cells; IL, interleukin; TGF, transforming growth factor.

effects on Treg and Th17 cells. In a rat model of liver transplantation, $\mathrm{Xu}$ et al (16) found that the proportion of Treg cells in peripheral blood mononuclear cells in the rapamycin treatment group was higher compared with the group treated with tacrolimus. Hajkova et al (17) reported that the inhibitory effects of BM-MSCs on CD4 ${ }^{+} \mathrm{ROR} \gamma \mathrm{t}^{+} \mathrm{Th} 17$ were significantly reduced after treatment with tacrolimus. The addition of rapamycin significantly reduced the expression of IL-17, whereas rapamycin significantly increased the expression of Foxp3 in the co-culture of MSCs and $\mathrm{CD}^{+} \mathrm{T}$ cells. In the present study, the proportions of Treg cells treated with different immunosuppressants resulted in opposite changes; the proportion of Treg cells decreased when treated with tacrolimus but increased when treated with rapamycin. Conversely, the proportion of Th17 cells notably decreased when treated with rapamycin, whereas a significant effect on the proportion of Th17 cells was not observed when treated with tacrolimus. However, there was no difference in the proportions of Treg cells amongst the cells treated with various concentrations of either tacrolimus or rapamycin.

Cytokines serve an important role in the regulation of the Treg/Th17 balance mediated by MSCs. The TGF- $\beta$ receptor is expressed on the surface of T cells and TGF- $\beta$ is an important cytokine involved in the differentiation and proliferation of $\mathrm{CD}^{+}{ }^{+} \mathrm{T}$ cells into Treg cells. MSCs can secrete TGF- $\beta$ and increase the proportion of Treg cells, and TGF- $\beta$ can amplify the inducing effect of MSCs on the differentiation of other cells into Treg cells (18). If the expression levels of Foxp3 in Treg cells are reduced, MSCs lose their ability to increase the proportion of Treg following the addition of a TGF- $\beta$ receptor antagonist in a co-culture of MSCs and $\mathrm{CD}^{+} \mathrm{T}$ cells (19). Treg cells are highly dependent on IL-2. Specific blocking of the IL-2 receptor in a co-culture of adipose-derived MSCs and $\mathrm{CD}^{+} \mathrm{T}$ lymphocytes, resulted in the inhibition of IL-2 uptake from the culture medium and this reduced the ability of MSCs to promote differentiation of Treg cells (20). When excessive exogenous IL- 2 was added to $\mathrm{CD}^{+} \mathrm{T}$ cells, a dose-related decrease in the proportion of $\mathrm{CD} 4^{+} \mathrm{IL}-17^{+} \mathrm{T}$ cells was observed, whereas the proportion of CD4 $4^{+} \mathrm{IL}-17^{+} \mathrm{T}$ cells was increased following the addition of an IL-2 blocker (21). The present study found that blocking of TGF- $\beta$ and IL-2 resulted in a reduced proportion of Treg cells, and the effect of IL-2 blockers was more prominent. Similarly, the expression of IL-17 significantly decreased when cells were treated with an IL-2 blocker. Thus, IL-2 serves a key role in the regulatory effect of MSCs on the Treg/Th17 balance.

The present study had a number of limitations. Firstly, the concentration range of immunosuppressants used in the present study was similar to the concentrations used in the clinic, therefore, a very narrow range of concentrations was used. This may partly explain the non-significant differences between different concentrations of immunosuppressants. Second, the differences in MSC concentrations between groups were relatively small, resulting in non-significant results.

In conclusion, BM-MSCs can promote the proliferation of both Treg and Th17 cells, but increased concentrations of BM-MSCs can inhibit the proliferation of both of these cells. This effect was notably influenced by the concentration of MSCs and the types of immunosuppressants added. In the cell culture, MSCs themselves secrete certain cytokines, which may serve as a potential mechanism to influence the immune environment. The future direction of studies from our lab will focus on how to regulate the balance of Treg/Th17 in favor of immune tolerance. 


\section{Acknowledgements}

Not applicable.

\section{Funding}

The present study was supported by the National Nature Science Foundation of China (grant. no. 81570592) and the Nature Science Foundation of Tianjin (Tianjin, China; grant. no. 17JCYBJC27500).

\section{Availability of data and materials}

The datasets used and/or analyzed during the current study are available from the corresponding author on reasonable request.

\section{Authors' contributions}

WG designed the study. KW performed the experiments, analyzed the data and wrote the manuscript. YJS and ZLS analyzed the data and revised the manuscript. BW, CLZ and WL performed the experiments. All authors contributed to the interpretation of the study.

\section{Ethics approval and consent to participate}

The present study was approved by Ethics Committee of Tianjin First Center Hospital (Tianjin, China) and was performed in accordance with the principles of $3 \mathrm{R}$ and those described in Experimental Animal Welfare Ethics Review Guide of China (GB/T 35892-2018).

\section{Patient consent for publication}

Not applicable.

\section{Competing interests}

The authors declare that they have no competing interests.

\section{References}

1. Mohammadpour H, Pourfathollah AA, Zarif MN and Tahoori MT: TNF- $\alpha$ modulates the immunosuppressive effects of MSCs on dendritic cells and T cells. Int Immunopharmacol 28: 1009-1017, 2015.

2. Romano M, Fanelli G, Tan N, Nova-Lamperti E, McGregor R, Lechler RI, Lombardi G and Scottà C: Expanded regulatory T cells induce alternatively activated monocytes with a reduced capacity to expand Thelper-17 cells. Front Immunol 9: 1625, 2018.

3. Özdemir AT, Özgül Özdemir RB, Kırmaz C, Sarıboyacı AE, Ünal Halbutoğlları ZS, Özel C and Karaöz E: The paracrine immunomodulatory interactions between the human dental pulp derived mesenchymal stem cells and CD4 T cell subsets. Cell Immunol 310: 108-115, 2016

4. Heidt S, Segundo DS, Chadha R and Wood KJ: The impact of Th17 cells on transplant rejection and the induction of tolerance. Curr Opin Organ Transplant 15: 456-461, 2010.
5. Sun Z, Li T, Wen H, Wang H, Ji W and Ma W: Immunological effect induced by mesenchymal stem cells in a rat liver transplantation model. Exp Ther Med 10: 401-406, 2015

6. Gharibi T, Ahmadi M, Seyfizadeh N, Jadidi-Niaragh F and Yousefi M: Immunomodulatory characteristics of mesenchymal stem cells and their role in the treatment of multiple sclerosis. Cell Immunol 293: 113-121, 2015.

7. Kim N and Cho SG: Overcoming immunoregulatory plasticity of mesenchymal stem cells for accelerated clinical applications. Int J Hematol 103: 129-137, 2016.

8. Zhou Y, Yang X, Zhang H and Jiang J: The roles of Thelper type 17/regulatory $\mathrm{T}$ cells in acute rejection after liver transplantation in rats. Transplantation 99: 1126-1131, 2015.

9. Liu X, Ren S, Qu X, Ge C, Cheng K and Zhao RC: Mesenchymal stem cells inhibit Th17 cells differentiation via IFN-Y-mediated SOCS3 activation. Immunol Res 61: 219-229, 2015.

10. Tang J, Yang R, Lv L, Yao A, Pu L, Yin A, Li X, Yu Y, Nyberg SL and Wang $X$ : Transforming growth factor- $\beta$-expressing mesenchymal stem cells induce local tolerance in a rat liver transplantation model of acute rejection. Stem Cells 34: 2681-2692, 2016.

11. Rozenberg A, Rezk A, Boivin MN, Darlington PJ, Nyirenda M, Li R, Jalili F, Winer R, Artsy EA, Uccelli A, et al: Human mesenchymal stem cells impact Th17 and Th1 responses through a prostaglandin E2 and myeloid-dependent mechanism. Stem Cells Transl Med 5: 1506-1514, 2016.

12. Rashedi I, Gómez-Aristizábal A, Wang XH, Viswanathan S and Keating A: TLR3 or TLR4 activation enhances mesenchymal stromal cell-mediated treg induction via notch signaling. Stem Cells 35: 265-275, 2017.

13. Sioud M, Mobergslien A, Boudabous A and Fløisand Y: Evidence for the involvement of galectin-3 in mesenchymal stem cell suppression of allogeneic T-cell proliferation. Scand. J Immunol 71: 267-274, 2010.

14. Chen W, Huang Y, Han J, Yu L, Li Y, Lu Z, Li H, Liu Z, Shi C, Duan F and Xiao Y: Immunomodulatory effects of mesenchymal stromal cells-derived exosome. Immunol Res 64: 831-840, 2016.

15. Qu X, Liu X, Cheng K, Yang R and Zhao RC: Mesenchymal stem cells inhibit Th17 cell differentiation by IL-10 secretion. Exp Hematol 40: 761-770, 2012.

16. Xu G, Wang L, Chen W, Xue F, Bai X, Liang L, Shen X, Zhang M, Xia D and Liang T: Rapamycin and tacrolimus differentially modulate acute graft-versus-host disease in rats after liver transplantation. Liver Transpl 16: 357-363, 2010.

17. Hajkova M, Hermankova B, Javorkova E, Bohacova P, Zajicova A, Holan V and Krulova M: Mesenchymal stem cells attenuate the adverse effects of immunosuppressive drugs on distinct $\mathrm{T}$ cell subopulations. Stem Cell Rev Rep 13: 104-115, 2017.

18. Yang JX, Zhang N, Wang HW, Gao P, Yang QP and Wen QP: CXCR4 receptor overexpression in mesenchymal stem cells facilitates treatment of acute lung injury in rats. J Biol Chem 290: 1994-2006, 2015.

19. Tang RJ, Shen SN, Zhao XY, Nie YZ, Xu YJ, Ren J, Lv MM, Hou YY and Wang TT: Mesenchymal stem cells-regulated Treg cells suppress colitis-associated colorectal cancer. Stem Cell Res Ther 6: 71, 2015.

20. Engela AU, Hoogduijn MJ, Boer K, Litjens NH, Betjes MG, Weimar W and Baan CC: Human adipose-tissue derived mesenchymal stem cells induce functional de-novo regulatory $\mathrm{T}$ cells with methylated FOXP3 gene DNA. Clin Exp Immunol 173: 343-354, 2013.

21. Laurence A, Tato CM, Davidson TS, Kanno Y, Chen Z, Yao Z, Blank RB, Meylan F, Siegel R, Hennighausen L, et al: Interleukin-2 signaling via STAT5 constrains T helper 17 cell generation. Immunity 26: 371-381, 2007.

(7) $\odot$ This work is licensed under a Creative Commons Attribution-NonCommercial-NoDerivatives 4.0 International (CC BY-NC-ND 4.0) License. 